\title{
Practice and Exploration of Cultivating Mode of Students' Innovation Ability of Engineering Universities
}

\author{
Qiangtian $\mathrm{Li}^{1 *}$
}

\author{
${ }^{1}$ Jiangsu University of Science and Technology \\ Zhenjiang, Jiangsu, 212003 \\ *E-mail: lqttw@163.com
}

\begin{abstract}
Cultivation of students' innovation ability of engineering university is very important for the society and educators. This paper reconstructs the cultivation mode of fostering the innovation of college students by integrating every key element in nurturing their innovation and making the element function in an efficient mechanism. Furthermore, the existing cultivation mode are proposed to be optimized to improve the effectiveness of cultivation. Such an innovation cultivation mode can help to promote the cultivating efficiency and effectiveness of students' innovation ability of engineering universities.
\end{abstract}

Keywords: innovation ability, cultivation mode, engineering university

\section{INTRODUCTION}

It has become the important strategic measure of the development of the economic society and target of the intensified higher education reform that quality talents of the following characters should be cultivated to better serve the society in the aspect of social advances and economic development. They have strong innovation senses, abilities and qualities; they possess abundant innovation knowledge, composite knowledge structure and pioneering character; they are good at innovation and dare to create.

The cultivation mode of the innovation ability of university students centers on cultivating their creativity. It tries to improve students' understanding and change their views on education by expanding their curriculum and developing multiple subjects simultaneously, reforming teaching strategies, using modern teaching equipment, developing practice teaching, establishing a platform for practice and setting up a system to guarantee that students' creativity be cultivated efficiently. This mode aims to develop the various abilities of college students, such as their ability to learn, to put knowledge into practice, to judge, to integrate and to create. It reconstructs the cultivation mode of fostering the innovation of college students by integrating every key element in nurturing their innovation and making the element function in an efficient mechanism. It also optimizes the existing cultivation mode and improves the effectiveness of cultivation.

\section{NEW IDEAS OF CULTIVATING STUDENTS' INNOVATION ABILITY OF ENGINEERING UNIVERSITIES}

Establishing scientific and proper cultivation mode requires university administrators, teachers and students to raise their understanding and to transform their thoughts on education. They should form an idea of fostering innovation, abide by the teaching rule of "people foremost" and follow the cultivation principle that the integrity and subjectivity in nurturing university students' innovation ability should be guaranteed.

\subsection{Establishment of educational concept combining with engineering philosophy}

Universities should alter the traditional educational concept to view the contemporary engineering education from the aspect of modern engineering and dialectical thinking to put forward a reasonable goal to improve students' practical ability on a scientific base.

It is significant that we follow the guidance of engineering philosophy, grasp the characteristics and essence of modern engineering, set up a general engineering education concept. Therefore the quality structure of the future engineers could be reconstructed and a number of the qualified future engineers who meet 
the requirements of the times could be trained. We must examine and recognize engineering education from the angle and at the level of philosophy. The traditional engineering education which is conditioned to imitation not innovation, is adept at art but weak in function and structure design, emphasizes the rigidity over the flexibility in manufacturing system should be altered. We should establish the sense of great engineering, construct modern practice teaching system and improve students' philosophical thinking and innovation practical ability to ensure the cultivation of engineering talents meet the need of the new-type industrialization and the building of the innovative country.

\subsection{Orientation scientifically with goal of cultivating innovation ability}

The target position of development and the talent training standards of the university are key to the school-running orientation as well as the top design of the university. From the genre of personnel training, it could be roughly divided into two types: academic personnel training and application-oriented personnel training. Academic education mainly focuses on cultivating people that engage in scientific research, while application-oriented education trains people who are more suitable for such jobs: technical, developing, promotional, managing, administrating, social working, teaching and so on. Higher engineering education is a professional education with technical science as its main disciplinary foundation and fostering engineers as its goal. It shares the common characteristics of high education in its specialty, innovation and depth. ${ }^{[1]}$ It also has the individual feature of application, technology and application. The type and level of people it cultivates could be evaluated in the whole process of engineering practice.

\section{ESTABLISHMENT OF EFFECTIVE INNOVATION CULTIVATION SYSTEM}

Establishing the cultivation system of the technical innovation ability of university students is a process of developing their innovation ability by using the systematic principle, which means to form a thinking paradigm in those aspects: organization and coordination, training guidance, practical operation, supervision and inspection, evaluation and assessment. In general, it includes three systems and one kernel (as illustrated in Fig. 1).

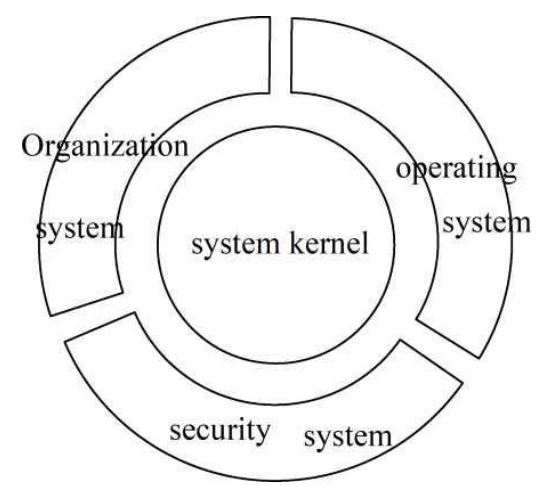

Fig.1 innovation cultivation system proposed

\subsection{Kernel of the cultivation system of innovation ability promotion}

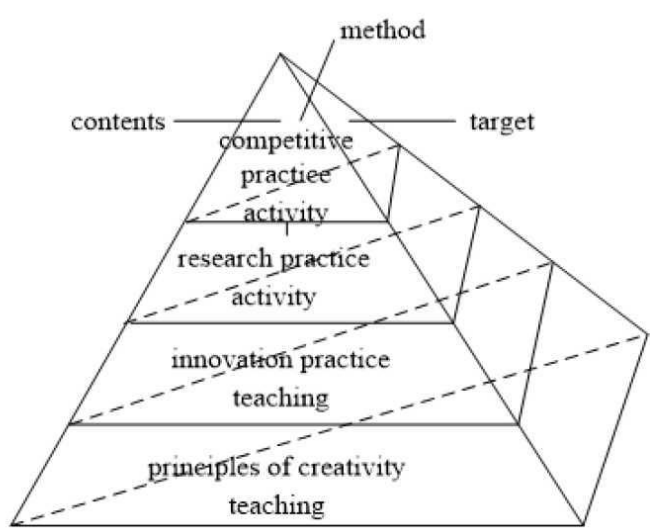

Fig.2 Kernel of the cultivation system for innovation ability promotion

Focusing on the target of training students with solid foundation, strong professional competence, high comprehensive abilities and global vision, we learn from the training pattern and mode of famous universities home and abroad and intensify our teaching contents and curriculum system reform. ${ }^{[2]}$ After exploration and practice, we have formed a kernel of the system for cultivation engineering students' innovation ability. The training system resembles the "pyramid" in a step-by-step mode, in which four levels are included(see Fig. 2): (1) Fundamental level: through teaching students of the principles of creative studies, students grasp the concept and element of creative studies as well as the pattern in the creative activity; stimulate college students' enthusiasm for innovation in the process of teaching them the basic ideas, developing patterns, classic cases, experience in innovation, strategic measures and solutions of some concrete creative activity like theory innovation, system innovation, technical innovation, etc. (2) Application level: mandatory laboratory lesson should be combined with optional laboratory lesson for cross-major students and curricular experiment should also be combined with extracurricular practice. It means students should 
perform experiments in the university and they should also go to enterprises to be interns to put their professional knowledge and innovation accumulation into practice which is a good chance to combine practice teaching and scientific research together. (3)Design level: following the agreed targets and parameters, students with the help of their teachers design technological schemes. They carry out a series of experimental research projects which are relative to their courses to further improve their innovation ability. (4)Innovation level: it refers to innovation experiments based on all kinds of academic competitions, innovation experiment proposals and training projects of scientific research.

\subsection{Organization system of cultivation of innovation ability promotion}

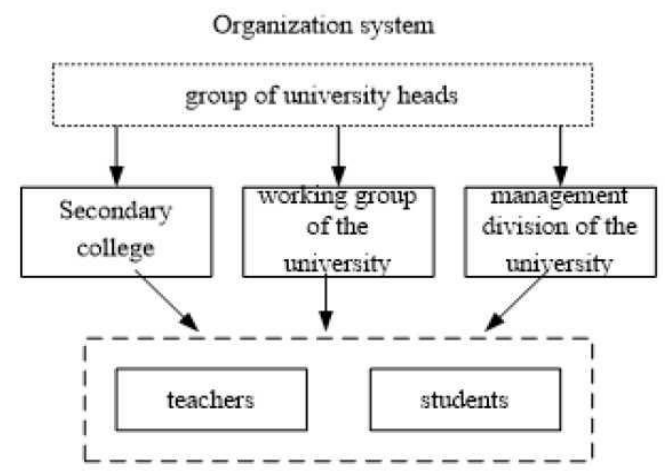

Fig. 3 Organization system of cultivation of innovation ability promotion

Organized by the administrators of the university, an organization system of cultivating the innovation ability of students is formed with the leaders of relative divisions like dean's office, office of science and technology, students' affairs division, financial department and so on participating in it, as is shown in Fig.3. Its main functions are:

(1) Leading the planning and designing, organization and coordination, supervision and inspection, evaluation and acceptance of the innovation cultivation activities.

(2) We would like to strengthen the publicity of training the technological innovation ability of university students to further clarify the actual meaning of it to all teachers and students in the university and to create a good atmosphere in which much attention would be given to cultivating the innovation ability of students.

(3) Work out detailed plans to outline, design and guide the work of cultivating the technological innovation ability of university students.

(4) Coordinate man power and financial resources to provide service
Teaching secretary, counselors and relevant teachers are members of the innovation ability training group. Their job includes organizing and running the technological innovation program, managing and allocating the fund for students' innovation activity, awarding students with credits, contacting experts to give guidance and review to the technological innovation program of the students.

\subsection{Running system for cultivation of innovation system promotion}

running system

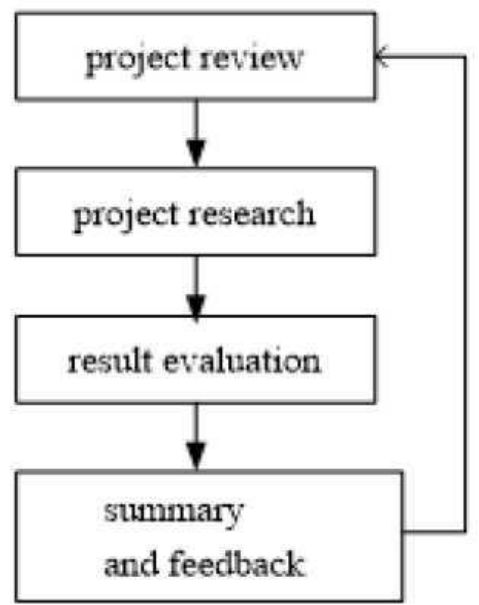

Fig. 4 running systems for the cultivation of innovation system promotion

The running system is an important part in making the cultivation system run smoothly. Take the innovation program for undergraduates as an example: (1) complete program evaluation: basing on the working group of innovation program for undergraduates and completing the pool of review experts to make the review, guidance and supervision running smoothly. (2) lay emphasis on the management of the process: carry out a process of "three defense, two symposia and one weekly work log". By organizing capstone presentations, mid-term inspections and concluding presentations, students who lead the project would have a strong appreciation of the contents of the project, the expected goals, the work arrangements and research findings. Thus it will make sure all the research work of each project would run smoothly.(3) Emphasize the evaluation of the results. We should stress the modeling effect of the key research projects to promote the overall research work to achieve the desired results. We should also standardize the selecting procedure of key projects, setting rules and regulations in managing the key projects and identify the goals for closing the key projects. (4) Strengthen summary and feedback. In order to make sure that the research work would turn out to be fruitful, it is 
necessary to identify the goals for closing each project and to understand research requirements of each stage. Through the periodical examinations to fulfill the research of each stage, we need to implement the elimination system, the funding adjustment system and the appraisal system of concluding results.

\subsection{Support system for cultivation of innovation system promotion}

Support system

Management system

Personnel

Funding raising

Laboratory opening

Credit system

Fig. 5 Support system for cultivation of innovation system promotion

Sound work performance needs the support of strong policy and the guarantee of effective mechanism. An instructive support and stimulating system should be established to make sure the technical innovation of university students would develop in an standardized, orderly and sustainable way and to encourage as many teachers and students as possible to take part in it. With the existence of the system, the innovation activities of students would be regular, institutionalized and scientific. ${ }^{[3]}$

On the basis of undergraduates' innovation credit system of the university, scientific incentive policies of innovation education which includes students, teachers and laboratories should be made and an effective and entirely open base for innovation training should also be set up.

The technical innovation activities of university students need the support of personnel, money and a lot more else, in which money is the most essential element. Apart from funding from the government and social donation, our university is broadening the financial resources to support the technical innovation activities.

\section{COHESIVE COUPLING SYSTEM OF IN-CLASS-TEACHING AND AFTER-CLASS EXPERIENCE}

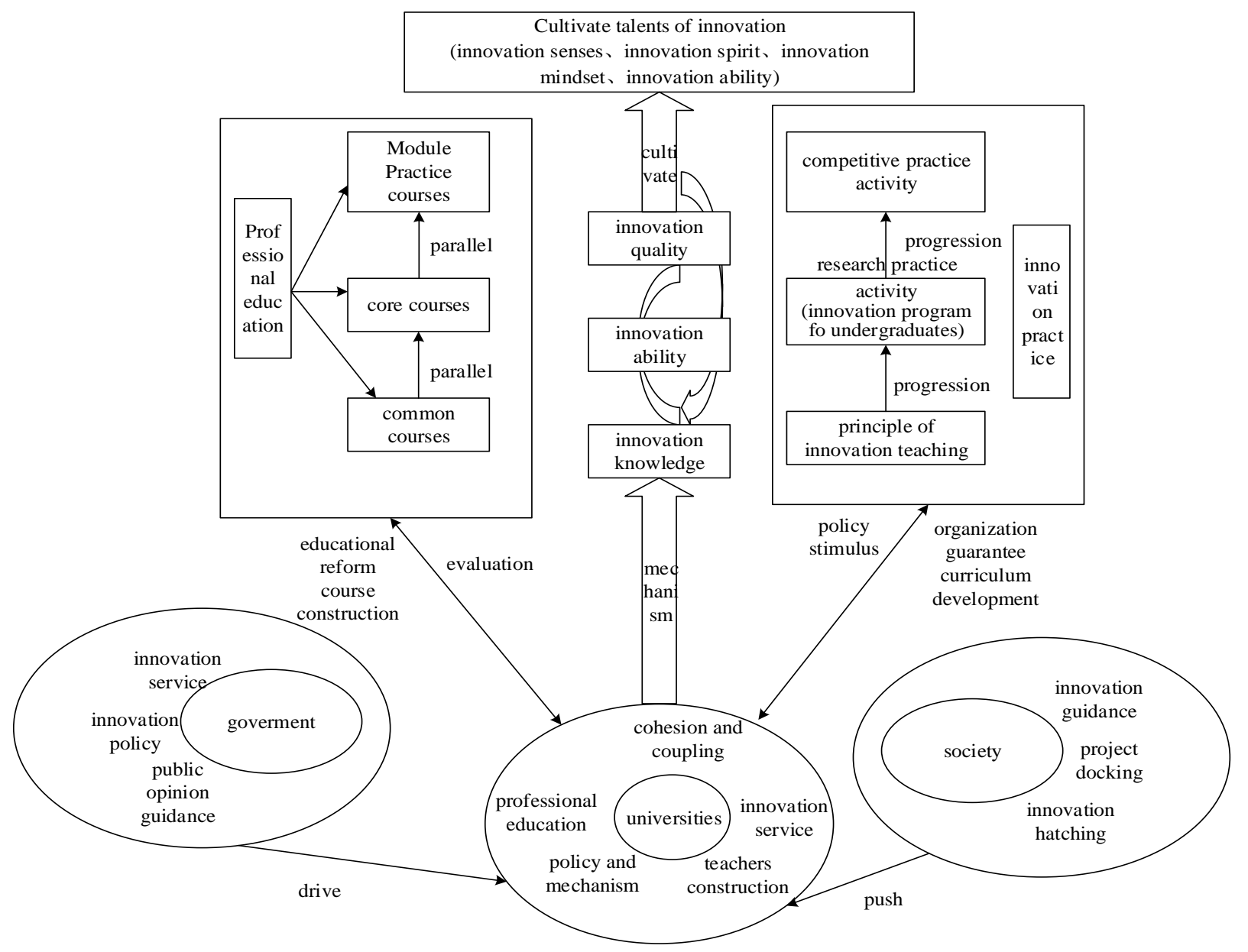

Fig. 6 cohesive coupling system of in-class-teaching and after-class experience 
As illustrated in Fig. 6, the proposed cohesive coupling system of in-class-teaching and after-class experience is a structure of cultivating talents of innovation. It resembles a DNA double helix structure consisting of two chemical bonds and a single strand. The professional education bond is comprised of the common courses, the core courses and the module practice courses. While innovation basic principles, research practice activities and competitive practice activities constitute the innovation education bond. ${ }^{[4]}$ These two bonds correspond to each other through innovation basic principles integrating into the common courses, the core courses permeating into research practice activities and competitive practice activities interacting with the module practice courses. This system nurtures senses of innovation, accumulates innovation knowledge and polishes innovation skills. The working mechanism strand connects the professional education bond and the innovation education bond, in which the big ring cases the small ring, in other words, the small ring is embedded in the big ring. The rings are inter-connected, opposite concentric. They mutually improve each other, cohere and couple and rise in a spiral. Talents who are of innovation senses, spirits, mindsets and abilities are eventually cultivated.

To expand space for cultivating the innovation ability of university students, a "four combinations" platform for technical innovation should be set up. It means theoretical learning in classroom should be combined with social practice, curricular innovation education should be combined with extracurricular innovation practice, course learning should be combined with technical competitions and bases within the university should be combined with those outside the university. ${ }^{[5]}$ In consideration of the characteristics of students of different years, technical innovation activities should be carried out accordingly in various stages. Dynamic management should be applied to it to form a feasible running mechanic for students' technical innovation activities to accelerate the development of technical innovation of students.

\section{CONCLUSIONS}

Cultivation of students' innovation ability of engineering university is very important for the society and educators. This paper reconstructs the cultivation mode of fostering the innovation of college students by integrating every key element in nurturing their innovation and making the element function in an efficient mechanism. Furthermore, the existing cultivation mode are proposed to be optimized to improve the effectiveness of cultivation. Such an innovation cultivation mode can help to promote the cultivating efficiency and effectiveness of students' innovation ability of engineering universities.

\section{ACKNOWLEDGMENTS}

This work is Funded by the "Jiangsu University Philosophy and Social Science Research Foundation, China (No.: 2017SJB1106)

\section{REFERENCES}

[1] Lin X. Research on the innovative talents training mode of college students based on Innovation Competition $[\mathrm{J}]$. Jiangsu Higher Education,2015(2): 132-134

[2] Zheng Y.H. Carrying out the innovation plan of college students to lead and promote the reform of talent training mode $[\mathrm{J}]$.Chinese Higher Education,2012(18).

[3] Zhang L.M. The construction of College Students' innovation ability training system in the new situation[J].University Education, 2016(6): 16-17

[4] Su Y.R. Research on the cultivation mode of College Students' innovative ability [D]. Wuhan University of Technology, 2013:63-65

[5] $\mathrm{Xu}$ Z.S. Research on the cultivation of innovative ability of second class and engineering students [D]. Fujian Normal University, 2012:22-25 